\title{
Decolonizar o corpo: o Teat(r)o Oficina e a Universidade Antropófaga ${ }^{1}$
}

\section{Decolonizing the body: Teat(r)o Oficina and the Anthropophagical University}

Marcelo de Trói ${ }^{2}$

Leandro Colling ${ }^{3}$ 


\section{Resumo}

A partir do procedimento cartográfico proposto por Deleuze e Guattari (1995), o artigo sinaliza que o projeto decolonial passou a ser marca do Teatro Oficina, dirigido por José Celso Martinez Corrêa. Essa característica está presente na montagem de 1967 de O Rei da Vela (1933), de Oswald Andrade, e de forma mais literal nas montagens de 1997 e 2016 de Para Dar Um Fim no Juízo de Deus (1947), de Antonin Artaud. Com sua fundação em 1958 e depois, com a criação da Universidade Antropófaga, em 2007, o Oficina tem sido local de construção desse saber-poder que relacionamos com os artivismos queer (Troi; Colling, 2016), com as ideias de conhecimento em Quijano (2005), Achinte (2006) e com a proposta de educação queer de Louro (2001).

Palavras-chave: Universidade antropófaga; Teatro Oficina; decolonização; artivismo queer

\section{Abstract}

Making use of the cartographical procedure proposed by Deleuze and Guattari (1995), this paper shows how the decolonial project became a trademark of the Teatro Oficina, under the command of José Celso Martinez Corrêa. As so, it is a perceivable feature in $O$ Rei da Vela (1933), by Oswald de Andrade, 1967's Oficina theatrical show and-more patently-in Para Dar Um Fim no Juizo de Deus (1947), by Antonin Artaud, play staged in 1996 and 2016. Established in 1958 and opening of the Anthropophagical University in 2007 - the Oficina has been a construction site for the knowledge/power that we relate to queer artivisms (Troi; Colling, 2016), to Quijano's (2005) and Achinte's (2006) views on knowledge, and to Louro's (2001) queer education proposal.

Keywords: Anthropophagical University; Teatro Oficina; decolonization; queer artivism

\footnotetext{
${ }^{1} \mathrm{O}$ texto apresenta resultados parciais da pesquisa de Marcelo de Trói no mestrado do Programa Multidisciplinar de Pós-Graduação em Cultura e Sociedade também integra a pesquisa Outras políticas para o respeito às diferenças sexuais e de gêneros no Brasil hoje que está sendo realizada por pessoas que integram o grupo Cultura e Sexualidade - CuS

2 Mestrando no Programa Multidisciplinar de Pós-Graduação em Cultura e Sociedade, da Universidade Federal da Bahia (UFBA), e integrante do grupo de pesquisa em Cultura e Sexualidade - CuS. Desde 1998, acompanha as montagens do grupo e, de 1999 a 2000, integrou o elenco do Teatro Oficina. troi.marcelo@ ufba.br

${ }^{3}$ Doutor em comunicação e culturas contemporâneas e professor permanente do Programa Multidisciplinar de Pós-Graduação em Cultura e Sociedade, da Universidade Federal da Bahia, onde coordena o grupo de pesquisa em Cultura e Sexualidade (CuS). leandro.colling@gmail.com
} 
A cartografia, procedimento voltado para as processualidades (Deleuze; Guattari, 1995), parece eficaz para traçar o mapa relacional que aponta linhas de forças e fluxos da decolonialidade do corpo no trabalho do Teatro Oficina Uzyna Uzona, companhia criada na Faculdade de Direito do Largo de São Francisco em $1958 .{ }^{4}$ É a partir da colonialidade/modernidade que pretendemos centralizar, em termos de reflexão nesse artigo, os conhecimentos que gravitam no Teatro Oficina e em sua Universidade Antropófaga (UA). A UA é definida pela própria companhia como a "prática de transmissão de saber" do Oficina:

Dirigida por um antropófago - Zé Celso Martinez Corrêa -, tem como arte matriz o teat(r)o; e seus espetáculo são uzynas de contracenação de muitas artes, muitas línguas, atuando na construção de peças que, com suas ações, situações e personagens, são canais de interpretação do tempo presente. [...] a Universidade tem como superobjetivo a formação não somente de atores para o teatro, cinema ou $\mathrm{TV}$, mas atuadores na sociedade, nas zonas de conflito, áreas de risco, formados na experiência do estudo e contato com os pontos tabus, que impedem nossa evolução democrática para a liberdade, incorporando o ensino com crianças, adultos, através de experiências artísticas, filosóficas, científicas, e mergulhando nos temas tabus, evitados pela educação de péssimo padrão hoje (Portal Universidade Antropófaga, 2017, sp).

Estamos tratando de um território, não apenas em relação às "différance"5 da linguagem rasurada brazyleira ${ }^{6}$, e do papel precursor da companhia e sua influência nos artivismos queer ou das dissidências sexuais e de gênero (Troi; Colling, 2016). ${ }^{7}$ No Oficina, o corpo é tema recorrente, acontecimento permanente no trabalho desta que é uma das associações culturais mais antigas do Brasil, referência não apenas para o fazer teatral, mas também para a de outras subjetividades que tenham como base a quebra de normas, um saber-poder que tem o corpo como centralidade.

A cartografia tem a preocupação de estabelecer sentidos múltiplos em determinado território através de seus rizomas que são princípios de conexão e heterogeneidade. Qualquer ponto de um rizoma pode ser conectado a qualquer outro e deve sê-lo: "Cadeias biológicas, políticas, econômicas, colocando em jogo não somente regimes de signos diferentes, mas também estatutos de estados de coisas" (Deleuze; Guattari, 1995, p.14). Esse também parece ser o princípio de uma educação voltada para uma visão transdisciplinar e multirreferenciada presente na Universidade Antropófaga, centro de transmissão do Teatro Oficina.

Do primeiro nu frontal à simulação da devoração de corpos em rituais antropofágicos dionisíacos ou, de fezes, esperma e sangue colocados no palco, o Oficina tem restituído e ensinado, com estes procedimentos, uma visão de corpo vivo e pulsante ou ainda delirante, que bebe e ressignifica a cultura dos povos originários do país. ${ }^{8}$

\footnotetext{
${ }^{4}$ Em texto intitulado Antropofagia, dissidência e novas práticas: o Teatro Oficina, falamos dessa relação com as forças atávicas e compósitas desse território (Glissant, 2005). Essa mítica que é o próprio CsO - Corpo Sem Órgãos, (Deleuze; Guattari, 2012), também é maneira de interpretar e de se inter-relacionar do grupo. ${ }^{5} \mathrm{~A}$ différance é o movimento pelo qual a língua ou qualquer código se constitui historicamente como tecido de diferenças. É o que faz com que o movimento de significação não seja possível, a não ser que cada elemento que aparece sob a cena presente se relacione com outra coisa que não ele mesmo (Derrida, 1991). O termo desencadeia um complexo problema de tradução para o português. Em Portugal optou-se por diferância e no Brasil, por diferência.

${ }^{6}$ Assim como Glauber Rocha, Zé Celso também vai subverter o português usando "z" e "y" na sua escrita, como uma espécie de rasura.

${ }^{7}$ A teoria queer emerge numa tentativa de desnaturalizar as relações, colocando os fenômenos sobre a influência das relações culturais, revelando a pré-discursividade e a performatividade (Butler, 2003) que vão diferenciar os sujeitos. O marcador artivismo queer, ou artivismo das dissidências sexuais e de gênero, designa produções, apontam para uma radicalização dos discursos a respeito da desnaturalização das sexualidades em intersecção com questões de raça, de classe social, de geopolítica, de luta anticolonial.
} 
"Quando o português chegou/ Debaixo duma bruta chuva/ Vestiu o índio/ Que pena! Fosse uma manhã de sol/ O índio tinha despido/ O português": em Erro de Português, de 1925, Oswald de Andrade (2012) reflete sobre uma das consequências da invasão europeia. Adotar a vestimenta até os dias de hoje talvez seja uma das marcas mais evidentes da colonialidade ou, antes disso, expressão do tabu do corpo como um dos seus pilares.

Por decolonialidade entende-se a luta permanente contra as epistemologias e topus coloniais a partir da noção de "giro decolonial", que é a radicalização do argumento pós-colonial no continente a partir do século XXI. Defender a opção decolonial - epistêmica, teórica e política - significa "compreender e atuar no mundo, marcado pela permanência da colonialidade global nos diferentes níveis da vida pessoal e coletiva" (Ballestrin, 2013, p.89).

A permanência da colonialidade entre nós, seus mecanismos conscientes ou não, evidentemente perversos, só foi possível a partir da criação das Américas, considerada o primeiro espaço/tempo de um padrão de poder de vocação mundial, como afirma Quijano (2005). Para além das críticas de Cusicanqui a respeito do termo decolonial, dando preferência ao anticolonial, e também ao "extrativismo epistêmico" em relação a Quijano (Grosfoguel, 2016), é nele que vamos nos basear com o conceito de "sistema-mundo", ou "cistema-mundo", somando o pensamento de Quijano à noção de cisgeneridade ${ }^{9}$ tratada por Vergueiro (2016).

No "cistema-mundo" global se concentra a produção da hegemonia e seus agenciamentos e alianças, a ideia de norma, normatização e normalidade, mecanismos para sua permanente transmutação maquínica: adaptação para o controle de todas as formas de subjetividade, de cultura e de produção de conhecimento em detrimento de conhecimentos "naturalmente superiores"10.

Esse padrão mundial da história controla e cria relações sistemáticas com estruturas sob a hegemonia de instituições produzidas dentro desse padrão de poder:

Assim, o controle do trabalho, de seus recursos e de seus produtos, está a empresa capitalista; no controle do sexo, de seus recursos e produtos, a família burguesa; no controle da autoridade, seus recursos e produtos, o Estado-nação; no controle da intersubjetividade, o eurocentrismo (Quijano, 2005, p.123, grifo nosso).

A construção desse saber-poder deve-se, principalmente, pela construção do conceito de "raça" (índios, negros, mestiços), essa suposta "diferença de estrutura biológica" que é o elemento constitutivo fundacional das relações de dominação do mundo colonial. Eles encontram seus próprios agenciamentos nas instituições produzidas dentro desse saber-poder como escolas, igrejas, repartições públicas e privadas, salas de jantares e ruas, essas últimas especialmente produzidas para o livre trânsito e domínio da carrocracia ${ }^{11}$.

\footnotetext{
${ }^{8}$ Para uma leitura do Oficina e Zé Celso como entidade cultural, ver o trabalho de Pires (2005). Para uma visão etnográfica do trabalho da companhia com o corpo, ver a dissertação de Sousa (2013). Para uma leitura deleuziana dos efeitos da companhia nas subjetividades, ver o trabalho de Limongi (2008).

${ }^{9}$ Cisgênera é a pessoa que se identifica com o gênero que lhe foi atribuído quando de seu nascimento, ou seja, a pessoa não-transgênera. Em termos de normatividade, a cisgeneridade é o "normal" ante a transgeneridade, que ainda é patologizada.

${ }^{10}$ Parte-se da ideia de que a modernidade/colonialidade cria uma referência de normalidade a partir da visão eurocêntrica, na qual, tudo que é diferente dessa cultura passa a ser visto como inferior, anormal, selvagem, bárbaro.
} 
São nesses elementos de dominação e nos pontos estruturais, a saber: empresa capitalista, família burguesa, Estado-nação e eurocentrismo, que criaremos as sínteses conectivas com a crítica dos espetáculos do Oficina, por onde vai operar a construção de conhecimentos dissidentes da Universidade Antropófaga.

\section{O despertar para o corpo}

Na narrativa do diretor, o endereço da companhia, Rua Jaceguai, foi designado assim primeiramente pela relação com os povos Tupy:

No início eram os Tupys os que deram o nome da rua: os come-cabeça $=$ os Jaceguay. Os Bandeirantes tomaram estas terras do Bexiga, que depois vieram pras mãos de Libertas, uma escrava que ganhou do seu senhor alforria e os domínios do Barão da Jaceguay. Era um Quilombo que chegava até a avenida Paulista: 'A Chácara do Bechiga'. Há documentos com os herdeiros de Libertas. Mas estas terras foram de novo griladas pelos emigrantes enriquecidos e viraram "vilas" italianas. Depois cortiço, cabeças de porco, no fim dos anos 40 foram plantadas cantinas e teatros. Nos 50 funcionava onde é o Oficina, um teatro espírita mesa branca: 'Novos Comediantes' [...] (Martinez Correa; Bardi; Elito, 1999, p.26).

Mais tarde, essa conexão com uma tribo indígena somará voz à Revolução Caraíba proposta por Oswald de Andrade em seu Manifesto Antropófago, de 1928, que se tornará efetivamente um espetáculo da companhia em 2011: Macumba Antropófaga. ${ }^{12}$

O trabalho do grupo segue por linhas de fuga que a todo momento obrigam a uma nova desterritorialização. Com encenações de textos autorais como Vento Forte Para um Papagaio Subir, em 1958, passam a textos como As Moscas, em 1959, de Jean Paul Sartre (1943), numa admiração do próprio Zé Celso pelo Existencialismo. ${ }^{13}$ Ainda em 1959, A incubadeira, texto de Zé Celso, é o espetáculo em que começa a libertação do grupo que "tenta quebrar o clichê do corpo, o clichê do palco italiano, o clichê da família":

"Romper com a família é uma coisa muito séria, muito séria! Até hoje esse problema é atualíssimo: a morte da família, a morte da instituição familiar. Enquanto houver família, cada geração, de um jeito ou de outro, terá que passar por isso" (Martinez Correa, 1998, p.33-34)

Com A Engrenagem, de Jean Paul Sartre (1948), primeiro espetáculo proibido pela censura, antes mesmo da ditadura, em 1960, o grupo, de forma ambiciosa, pretendia "intervir ativamente" na política latino-americana (Nandi, 1989, p.24). Quando em 1963, o Oficina decide pela encenação de Pequenos Burgueses, de Máximo Górki (1902), está posto de forma consciente o rompimento com o "universo familiar, a discussão de valores da família" (Peixoto, 1982, p.274). Em 1966, com Os Inimigos, também de Górki (1906), o método stanislavskiano de análise de texto e laboratório

\footnotetext{
${ }^{11}$ Carrocracia é o regime despótico que envolve a indústria automobilística, a indústria do petróleo, a família burguesa e a lógica territorial da urbanidade, pensada para que o carro reine absoluto no espaço público em detrimento do sacrifício de pedestres e de outras mobilidades possíveis como a bicicleta.

${ }^{12}$ Novamente em cartaz no Teatro de junho a setembro de 2017.

${ }^{13}$ Corrente filosófica formulada no século XX, cuja maior referência é Jean Paul Sarte, e inspirada nas ideias de Kierkegaard (século XIX). O Existencialismo afirma a prioridade da existência sobre a essência. Nele, o indivíduo é forçado a tomar decisões que reforçam seu caráter racional.
} 
já é uma prática cotidiana no grupo, a partir do contato e das aulas do russo Eugênio Kusnet, ${ }^{14}$ que chega justamente na transição do grupo para a profissionalização, sendo responsável também pelo fomento de um local de aprendizado permanente que teria como símbolo a bigorna.

Em 1962, ao assistir Todo Anjo é Terrivel (Look Homeward, Angel), de Thomas Wolfe (1929), adaptação de Ketti Frings, a atriz Ítala Nandi voltava para Porto Alegre, mas com intenção de retornar no ano seguinte e trabalhar "nesta grande escola de arte que era o Oficina" (Nandi, 1989, p.25). Em 1967, a montagem de O Rei da Vela, de Oswald de Andrade, para além de marco Tropicalista, aprofunda a preocupação com o gesto e com o corpo, a partir dos laboratórios (exercícios físicos teatrais) com Luís Carlos Maciel, como explica a atriz Ítala Nandi:

Eram importantes os depoimentos pessoais baseados no gestual: queríamos estudar os gestos fundamentais que as pessoas adquirem em função de seus ofícios, ou seja, o gesto dos bancários, dos políticos, dos médicos, dos estudantes, etc. Havia nesses laboratórios uma fonte fantástica de aprendizado. Quantas coisas poderíamos entender através do corpo! [...] Numa noite, sentados no Bar Cervantes, Zé Celso e eu observamos todos os homens que entravam, ao subir o degrau, davam uma ajeitada no saco [...] concluímos que ajeitar o saco era uma verdadeira obsessão masculina. Mais tarde esse gesto foi estilizado e usado, em momentos precisos, pelos principais personagens de O Rei da Vela (Nandi, 1989, p.68-69).

O espetáculo O Rei da Vela fez mais do que inaugurar um teatro que havia sido destruído por um incêndio um ano antes, ${ }^{15}$ a montagem abria um fluxo para outras subjetividades já expressas no programa do espetáculo: "Tupi or not Tupi - That is the question". 16

Amparado pela teoria brechtiana, o espetáculo critica fortemente a empresa capitalista e a família burguesa. Heloísa de Lesbos, moça educada e preparada para ter um grande casamento, é obrigada a casar com o dono do novo capital após a crise: Abelardo I, agiota milionário (idem, p.84) fazia conchavos com o imperialismo, com o operariado, com todos. O espetáculo "esculhambava a subserviência, o espírito colonizado, o capachismo, tudo o que conhecíamos através da história e que agora aparecia nos laboratórios de Maciel". ${ }^{17}$ Naquele ano, a temporada foi tumultuada com críticos espantados. O público, dividido entre o fascínio e o ódio, era revistado toda noite. Ameaças diárias, agressões físicas aos atores até que um dia:

\footnotetext{
${ }^{14}$ Em depoimento, um dos fundadores do Oficina, Renato Borghi diz: "E era encantamento o Kusnet falar de todo esse processo de ator dele na Rússia, de Stanislavski. Ele já estava sistematizando uma série de coisas para começar a ensinar, mas ainda não tinha tido oportunidade (...) O Kusnet veio como ator e professor, ele teve um papel muito importante" (Peixoto, 1982, p. 271-272) Sobre a passagem de mestres pela escola da bigorna, também vale citar Renée Gumiel, dançarina da guerra civil espanhola, professora de dança no Oficina do final dos 90, essencial na preparação dos atores para o espetáculo Cacilda! (1998-2000). 15 "O fogo começou mais ou menos às $10 \mathrm{~h}$ da manhã de 31 de maio de 1966. Um pedaço de madeira em chamas atravessou o forro de eucatex e caiu na plateia. No teatro estavam o faxineiro Argemiro e o eletricista Domingos Fiorini. 0 teto desabou logo, os bombeiros conseguiram impedir apenas que 0 incêndio atingisse os prédios vizinhos. [...] Artistas, jornalistas, empresários e estudantes vieram logo ao local. Naquele mesmo instante começa uma nova etapa: renascer das cinzas?" (PEIXOTO, 1982, p.69).

${ }^{16}$ Do Manifesto Antropófago (1928) de Oswald Andrade em diálogo com "To be, or not to be", de Hamlet (1603), de William Shakespeare. Para Deleuze e Guattari, Hamlet também incorpora a lógica edipiana. "Você nasceu Hamlet?", perguntam os filósofos. "Por que retornar ao mito? Esta quinquilharia ideológica de que 0 mundo se serviu para construir todo o seu edifício cultural está em vias de perder seu valor poético, seu caráter mítico, porque, através de uma série de escritos que tratam da doença e, por conseguinte, das possibilidades de sair dela, o terreno encontra-se desentulhado" (Deleuze; Guattari, 2010, p.393). Ham-Let é a tradução para o texto shakespeariano criado por Zé Celo, Catherine Hirsh e Marcelo Drummond, para o espetáculo de seis horas que reinaugurou o Oficina, em 1993, após a reforma da arquiteta ítalo brasileira Lina Bo Bardi.

${ }^{17}$ Declaração de Renato Borghi em entrevista (Peixoto, 1982, p. 276).
} 
[...] alguns carros da polícia e quatro investigadores entraram no Oficina e levaram 'preso' nada mais nada menos que um imenso cilindro de madeira compensado que, como alusão fálica, era o 'pênis' de um grande boneco, retrato da burguesia brasileira, que o magnífico cenário de Hélio Eichbauer tinha na boca de cena à esquerda. Este 'pênis' era usado como um inusitado canhão [...] No dia seguinte, José Celso, Renato e eu fomos à Polícia Federal, prestamos um pequeno depoimento e, depois de assinarmos que o 'pênis' não mais seria usado em cena, voltamos pelas ruas de São Paulo trazendo de volta aquele grande e perigoso cilindro de madeira (Peixoto, 1982, p.75) [aspas do autor].

Com a montagem, o Oficina entra no que José Celso chamou de revolução cultural de descolonização completa do Brasil,

[...] retomando a Antropofagia da Cultura dos Índios Caetés que comeram o Bispo Português Sardinha que ia à Europa buscar mulheres brancas para cruzarem com os colonos portugueses. Com esta montagem devoramos o Teatro do Hemisfério Norte, comidos pelas culturas que assumimos em nosso corpo: a dos índios, dos escravos africanos, dos emigrantes que cozinharam a massa da mestiçagem dos Baixos do Brasil (Martinez Correa, 2012, p.212).

Para Quijano, a modernidade fez com que as relações da Europa com o resto do mundo fossem codificadas em jogos de novas categorias: "Oriente-Ocidente, primitivo-civilizado, mágico-mítico, irracional-racional, tradicional-moderno" (Quijano, 2005, p. 122). Nesses novos dualismos citados, as relações entre o corpo e o nãocorpo, na perspectiva eurocêntrica, tem estreita relação com raça e gênero e fazem parte da história do mundo cristão branco e sua ideia de primazia da alma sobre o corpo, sendo este objeto básico de repressão:

Esse novo e radical dualismo não afetou somente as relações raciais de dominação, mas também a mais antiga, as relações sexuais de dominação. Daí em diante, o lugar das mulheres, muito em especial, o das mulheres de raças inferiores, ficou estereotipado junto com o resto dos corpos, e quanto mais inferiores fossem suas raças, mais perto da natureza ou diretamente, como no caso das escravas negras, dentro da natureza. É provável, ainda que a questão fique por indagar, que a ideia de gênero se tenha elaborado depois do novo e radical dualismo como parte da perspectiva cognitiva eurocentrista (idem, p. 129).

Com o despertar para a violência eurocêntrica sobre os corpos, na constatação de que era necessário radicalizar o conhecimento sobre essa "máquina desejante", o Oficina dá prosseguimento às suas experiências com o corpo nas décadas seguintes. Em 1969, no espetáculo Nas selvas da cidade, de Bertold Brecht (1923), Ítala Nandi faz o primeiro nu frontal, o que se tornaria uma das marcas do grupo.

Com o mergulho na antropofagia de Oswald, não havia outro caminho para o Teatro Oficina senão experimentar sua proposta política. Gracias Señor é uma criação coletiva de 1972 que começa a deslocar a produção do Oficina para sua própria história (metateatro), o que se tornaria uma das características mais fortes do grupo. Mudando como em outros momentos, o nome da companhia passa a ser "Grupo Oficina Brasil em Re-Volição" (Peixoto, 1982, p. 188). O espetáculo, que já usava o que a companhia convencionou a chamar de Teato, ${ }^{18}$ era dividido em sete partes. $\mathrm{Na}$ 
segunda parte, intitulada Para onde vai essa energia? - Aula de Esquizofrenia, descreve-se:

Estamos divididos. Palco - Plateia. Atores - espectadores. Vamos fingir que essas divisões valem. Vamos aceitar até a forma de AULA (Descoberta na experiência da Universidade de Brasília). Nós professores - público Alunos. Um organismo crescendo vai realizando todas as suas potencialidades, mas submetido a uma pressão externa muito forte, tem seu crescimento atrofiado e sofre uma cisão tornando-se o organismo doente: esquizofrênico. ESQUIZOFRENIA=DIVISÃO [...] O Oficina sofreu um impacto esquizofrênico quando, tanto em Galileu como em Selva das Cidades, teve de conter sua potencialidade [...] A força produtiva, a nossa energia estava encarcerada, não cabia nas nossas relações de Produção [...] A Aula e Esquizofrenia demonstram as origens da Couraça do Sistema de Relações que escraviza, domina e castra a energia propulsora do movimento (Idem, p. $191-192)^{19}$.

Como se percebe, o devir escola está a todo tempo permeando a experiência da companhia. Na experiência radical e coletiva de Gracias Señor estava o embrião de montagens como Os Sertões, processo que vai de 2000-2007, da obra de Euclides da Cunha, publicada em 1902, que deságua na compilação desses saberes que culminam com a Universidade Antropófaga.

Há quem faça relação do happening de Gracias Señor com o grupo norte-americano Living Theater, contemporâneo do Oficina. Mas é preciso cuidado na análise dessa influência, já que são grupos contemporâneos e ambos criavam essa nova cena teatral mundial. O Oficina entra em contato com o Living na França quando seus integrantes se encontraram com Glauber Rocha, em 1971. A companhia de Julien Beck só veio ao Brasil graças ao convite do Oficina. Apesar das trocas mútuas entre eles, os conflitos e uma diferenciação dos trabalhos surgiram desde o primeiro encontro:

As discussões eram diárias. Eles colocavam a coisa assim: ou o Oficina entra na deles ou nada feito. Para nós, o interesse principal era o de analisar esse tipo de relação cultural que tínhamos com eles - essa doença colonial - e jogar tudo isso num processo de trabalho comum, criando com as nossas contradições [...] Você estava perante o Cacique puritano Julien Beck, e perante nós, o Caos. De um lado aquela coisa monolítica, bem-acabada, de computador; do outro o nosso processo demoníaco, confuso, contraditório. De um lado os americanos, de outro os brasileiros (Martinez Corrêa, 1998, p. 170-171).

\section{Em direção ao Corpo Sem Órgãos}

O Corpo Sem Órgãos ( $\mathrm{CsO}$ ) é um conceito criado por Deleuze e Guattari e narrado pela primeira vez nos escritos de Antonin Artaud (1896-1948). ${ }^{20}$ É nele que se assenta o que chamam de produção desejante, ou seja, é a superfície para o registro de toda produção de desejo: "Sobre o corpo sem órgãos as máquinas se engancham

\footnotetext{
${ }^{18}$ Sobre o te-ato, ver o livro de Armando Sérgio da Silva (2008). Teato: "atar e atuar", uma interpretação que rompe com a ideia da 4a parede (Troi; Colling, 2016, p.132).

${ }^{19}$ Identificado em Peixoto (1982) como "texto do Oficina", a linguagem aqui é bastante próxima aos conceitos criados por Deleuze e Guattari em Capitalismo e Esquizofrenia, nitidamente influenciando o grupo que passou por Paris em maio de 68, acontecimento que embala O Anti Édipo (1972).

${ }^{20}$ Para Dar Um Fim no Juízo de Deus, texto radiofônico criado por Artaud em 1947, que o Teatro Oficina levou para os palcos em 1997 e novamente em 2016.
} 
como outros tantos pontos de disjunção entre os quais tecem toda uma rede de sínteses novas que quadriculam a superfície" (Deleuze e Guattari, 2010, p.25).

Transformar a companhia em um grande agenciamento maquínico talvez não tenha sido a primeira ideia dos seus fundadores, mas esse caminho, tanto possível quanto inevitável, tem como meta a criação de um centro transmissor de conhecimento e, principalmente, uma decolonização das esferas públicas e privadas dominadas pela cartografia vigente (Rolnik, 2016).

Em O Anti-Édipo, Deleuze e Guattari (2010) não vão apenas estabelecer as relações entre capitalismo e esquizofrenia, numa tentativa ambiciosa de "destruir" Édipo, mas miram no cerne da questão: "Édipo é sempre a colonização continuada por outros meios, é a colônia interior, e veremos que, mesmo entre nós, europeus, ele é nossa formação colonial íntima" (idem, p.226). ${ }^{21}$

Se pensarmos em termos de "cistema-mundo" pautado, principalmente, pela normatização e naturalização das relações com o corpo e, consequentemente, com o gênero, sexo e raça, perceberemos que essa doxa, esse senso comum, rebate justamente na "falta" e na "castração". Édipo é o grande agenciamento da família, do Uno, da falta, o $(3+1)^{22}$ das sociedades neocolonizadas "que lhe inculcam, e que conseguem afinal o que a colonização apenas esboçou, um efetivo assentamento das forças do desejo sobre Édipo". ${ }^{23}$

Por isso, muito de Édipo se localiza no cu. "O primeiro órgão a ser privatizado, colocado fora do campo social, foi o ânus", e sendo assim, "se o falo tomou nossas sociedades a posição de um objeto separado que distribui a falta às pessoas dos dois sexos e organiza o triângulo edipiano, é o ânus que o separa assim". ${ }^{24}$ Com a transmissão da prática teatral desenvolvida pelo Oficina, o cu torna-se referência, peça chave para compreender o processo de decolonização do corpo em várias encenações da companhia.

Em O Banquete, montagem de 2011, a partir do clássico Diálogos de Platão (séc. V a.C.), na "transversão" de José Celso Martinez Corrêa, a Canção do Olho do Cu ${ }^{25}$ embala uma cena em que um ator interpretando Sócrates penetra outro com o dedo, como na indicação da rubrica no texto dramatúrgico:26"(Sócrates, põe saliva e seu dedo penetra o cu de Pausânias, que vai se abrindo como uma lona de Circo)". A canção também tem o propósito de ressignificar (algo central para as perspectivas queer) um conhecidíssimo insulto muito utilizado no Brasil, o famoso "vai tomar no cu". "Era um palavrão em tempos remotos/ Hoje é um conselho tântrico/ Todos temos, machos e fêmeas/ Vamos tomar no cu!", como dizem Sáez e Carrascosa (2011, p. 13), assim o Oficina "trata de ver o que o cu põe em jogo". "O cu parece muito democrá-

\footnotetext{
${ }^{21}$ Para uma leitura do Teatro Oficina a partir da psicanálise e o Narciso Ctônico em Os Sertões, ver tese de doutorado de Campbell (2013).

${ }^{22}$ Sobre "3 + 1", "4 (+n)" e "n-1": operações para uma outra "lógica" criada por Deleuze e Guattari para tratar de desmontar o pensamento edipiano: "A operação de Édipo consiste em estabelecer um conjunto de relações bi-unívocas entre, de um lado, o agente da produção, de reprodução e de antiprodução sociais e, de outro lado, os agentes da reprodução familiar dita natural. Esta operação chama-se aplicação. Tudo se passa como se se dobrasse uma toalha e os seus 4 (+n) cantos fossem assentados em 3 (3+1, para designar o fator transcendente que opera a dobragem)" (Deleuze; Guattari, 2010, p.139).

${ }^{23}$ Ibidem, p. 227.

${ }^{24}$ Ibidem, p.189-190.

${ }^{25}$ A respeito dos artivismo das dissidências sexuais e de gênero, ver $A$ Canção do Cu Elétrico, poema de Roberto Piva com o coletivo Casa Selvática, de Curitiba: https://www.youtube.com/watch?v=joJHZZbffME Último acesso em 10/03/2017.

${ }^{26}$ O Banquete (2011, p.23). Disponível em http://www.teatroficina.com.br/play/file3/16/o_banquete.pdf Último acesso em 10/03/2017. Para uma leitura do espetáculo Cacilda! (1998), de José Celso Martinez Correa, a partir das rubricas, ver Ramos (1999).
} 
tico, todo mundo tem um. Mas veremos que nem todo mundo pode fazer o que quer com seu cu" (idem, p. 14).

Em Para Dar o Fim no Juízo de Deus, de Antonin Artaud (1947), montada em 1997 e remontada em 2016, a companhia vai às últimas consequências na adaptação do texto radiofônico para colocar todos os fluxos da máquina desejante em cena: sangue, esperma e fezes. Os atores que operam essas cenas passam por um absoluto controle de suas máquinas. No momento certo, a máquina ânus estará pronta para liberar as fezes, ação que será transmitida pela internet e por todo o aparato de comunicação visual do Oficina:

Quando baixa a guarda, mesmo depois da apresentação, descobre-se que a afirmação da carne diante do incorpóreo, do homem diante de Deus, feita abusivamente na montagem, nada tem de gratuitamente chocante. Não faltam motivos para choque. Um ator, como dizer, defeca em cena. Outro se masturba até o fim. Outro tira seu sangue em seringa, que é por sua vez jorrado sobre uma ferradura. É a afirmação da carne - de um ritual de índios mexicanos, de descrucificação, contra a cruz do conquistador espanhol. Artaud revoltou-se contra Cristo, o próprio, que, diante de Deus, abdicou de seu corpo. Na montagem, é quando está mais presente a interpretação sarcástica, carnavalesca de Marcelo Drummond. É quem anuncia, às gargalhadas: "Deus é merda". No fim, Zé Celso, com uma atuação doce, carinhosa que só os mais rancorosos podem julgar ofensiva, anuncia que, agora que a matéria está vencendo e todos estão em favor do homem, é hora de virar o homem do avesso. Emascular o homem. Uma alegoria para a existência humana, mas sobretudo uma alegoria para o teatro, que não surge mais como vida, mas uma vida ao avesso, e maior (Sá, 1997, s/p).

Dos espetáculos encenados pelo Oficina, sem dúvida, o texto de Artaud é aquele em que a questão da corporeidade é o centro da narrativa, transformando-se em acontecimento pulsante na "cápsula revolucionária da cultura do corpo humano":

O grande poder de atração que a montagem irradia em direção ao espectador é sua pulsante e polimórfica corporeidade. As palavras de Artaud tomaram corpo no carne dos atores, precipitada, por sua vez, em puro verbo teatral. Após mostrar o parto do multiartista e intelectual francês, concebido como filho da tempestade, o Oficina entroniza Artaud-Marat (Pascoal da Conceição) em um vaso sanitário, de cujo cume ele fala - lendo o jornal do dia - sobre a América dos dominadores, beligerante e capitalista. O monólogo materializa o sêmen de um Artaud púbere, que remete à "prova do líquido seminal ou do esperma" a que os estudantes americanos se submetem "por causa de todas as guerras planetárias", e acaba convertido na dejeção que o próprio intérprete expele diante de todos. É como se o Oficina precisasse blasfemar contra o teatro psicológico ou metafísico, fazendo uso das extremidades do corpo de seus atores, loucos que falam pelo pênis e pelo ânus, em detrimento (da mesma raiz de "detrito") dos muitos discursos ajuizados e bem-pensantes que nos últimos tempos têm grassado por aí (Andrade, 2015, $\mathrm{s} / \mathrm{p})$.

Processos subjetivos que têm o poder de causar reverberações no socius, para pensar na máquina social de Deleuze e Guattari. Ciente desse agenciamento, a escrita poética e rasurada de Zé Celso a respeito da remontagem de Juízo de Deus também se junta a esse platô:

Fazendo esta peça revolucionária, penso: vai surgir uma Frente Ampla d pedaços $\mathrm{d}$ todos os partidos em defesa da democracia? Meu ser Zé Artaud, minha Perso- 
nagem, deseja Mais q uma FRENTE, uma RODA VIVA AMPLA d todas as Culturas Brazyleiras, Ianomanis, Tupys Guaranys d todas as Tribos, no movimento inevitável da vida no Planeta Ser Vivo Terra, com os Sem Teto, Sem Terra, Gays, Lésbicas, Trans, Afro Descendestes, Trabalhadores Inspirados, Mulheres Livres, Hackers, Menores d 16 anos, Favelados, Classe Média, alguns Pirados dos 1\% com suas Fortunas distribuídas. Nessa Roda tiramos todos os rótulos y somos com os bichos, águas, terras, seres vivos q juntos vamos democratizar a democracia, mudando democraticamente o sistema, até atingirmos a Anarquia Coroada y Tecnizada. Esse lixo q cacareja o impeachment, corruptores da própria Corrupção em nome do JUIZO D deus, hoje sob o comando d um Vampiro, ressuscitado, dando o desfecho á novela: será q o Crime foi cometido pelo Mordomo? Virão novos capítulos desta novela, mas nós continuamos com a mesma peça em cartaz. Uma peça d Artaud, é um Corpo sem Orgãos, quer dizer, como o mesmo movimento d intuscepção d Terra q renova-se livrando-se de seus agentes adversos (Martinez Correa, 2016, s/p).

\section{Conhecimento e lugar}

Achinte (2006) rastreia as implicações da emergência de formas de produção de conhecimento para que seja possível pensar em lógicas outras em relação projeto moderno e que não são geradas exatamente dentro da academia. A Universidade Antropófaga talvez nunca tenha status acadêmico, como outros centros de produção de conhecimento, e tão pouco esse é o desejo do corpo indisciplinar do Teatro Oficina.

Embora a companhia tenha patrocínio, os recursos não são suficientes para a elaboração desse trabalho de Teatro de Estádio. O Oficina jamais poderia ter sua arte sustentada pelo mercado que preza pela hegemonia de um tipo de arte que não problematiza a validade das normas, quiça a valorização de outras subjetividades e corporeidades. Ao mesmo tempo, o fato de serem patrocinados pelo Estado e de lidarem com temas tabus como nudismo, "drogas" (Sousa, 2013), instaura uma contradição dentro do organismo de vigilância estatal.

Para uma das timoneiras da companhia, Camila Mota, o Oficina se confirma como esse espaço de formação:

Somos uma companhia permanentemente instável - existe um núcleo criador -
cada vez maior, e artistas que passam pequenas temporadas conosco - sempre
bem vindos. Somos patrocinados pela Petrobrás, numa parceria que já dura 11
anos, e embora não dê para cobrir todos os gastos de um ano de manutenção do
espaço e dos grandes elencos - pois uma multidão custa muito caro, esse patrocí-
nio é fundamental para a perenidade do trabalho. Companhias permanentes, seja
o Teatro Oficina ou a Royal Shakespeare Company, são espaços de formação.
A Universidade Antropófaga é a nossa prática de transmissão de conhecimento
e eu gosto muito dessa ideia como direção para o trabalho, mesmo que não seja
um período de chamadas públicas de turmas, mas no nosso dia a dia, num estado
permanente de invenção (Nunes, $2017, \mathrm{~s} / \mathrm{p}$ ).

A interculturalidade proposta pela Universidad Intercultural de las Nacionalidades y Pueblos Indígenas, Amawtai Wasi, no Equador, parece ser uma proposta que cria linhas de semelhança com o projeto pensado para a UA:

A reflexão pedagógica partiu da problematização do conceito de 'uni-versidade' no sentido restritivo de um universo, para expandi-lo a uma visão múltipla de re- 
alidade polissêmica. Estas definições surgiram de um olhar detalhista das lógicas das comunidades negras, suas formas de ver o mundo em sentido integral e suas relações com a natureza [...] O multi é assumido como uma dimensão mesma da realidade, de maneira que o produtivo, o existencial, o cosmológico, o social e o cultural não estão desassociados, mas se inter-relacionam em um sentido de tensões, continuidades e rupturas criando um mundo plural (Achinte, 2006, p.69) ${ }^{27}$.

Achinte defende que não critiquemos o eurocentrismo apenas, mas que explicitemos as potencialidades de um pensamento vindo desde as profundidades dos povos subalternizados. Para ele, o "pós-ocidental", em que a Europa já não mais é o centro do mundo, deve ser forjado na memória dos grandes genocídios da modernidade: indígena, diáspora negra e o genocídio que começa com a gestão da modernidade.

Quando o Oficina estabelece Os Sertões como projeto para quase uma década (sem levar em conta os estudos que se inciaram para a realização da montagem ainda em 1972), está claro que importa para o grupo a visão dessa subalternidade. O massacre de Canudos (1897) é praticamente o marco do estabelecimento da República (1889) com sua ideia de Estado-nação e fundamental para a aliança entre o Estado e o Capital no Brasil.

Os Sertões foi um acontecimento, a grande chave de apreensão dos primeiros atores formados pelo que viria a ser Universidade Antropófaga. Esse livro que forma "gentes", sem o qual é impossível compreender a violência do Estado brasileiro, traz noções sobre assuntos interdisciplinares como a geografia, a filosofia, o militarismo, a antropologia, além de nos alertar sobre os males que a razão pode agenciar, como em Canudos.

$\mathrm{Na}$ direção de conhecimentos plurais e multidiversos também vai a ideia de uma educação queer, ${ }^{28}$ proposta por Guacira Lopes Louro (2001). O queer representa a diferença que não quer ser assimilada, portanto uma ação transgressiva e perturbadora. Uma pedagogia queer se distinguiria de programas multiculturais "bem-intencionados" com uma ideia de tolerância:

Uma pedagogia e um currículo queer estariam voltados para o processo de produção das diferenças e trabalhariam, centralmente, com a instabilidade e a precariedade de todas as identidades. Ao colocar em discussão as formas como o 'outro' é constituído, levariam a questionar as estreitas relações do eu com o outro. A diferença deixaria de estar lá fora, do outro lado, alheia ao sujeito, e seria compreendida como indispensável do próprio sujeito [...] Ao se dirigir para os processos que produzem as diferenças, o currículo passaria a exigir que se prestasse atenção ao jogo político aí implicado: em vez de meramente contemplar uma sociedade plural, seria imprescindível dar-se conta das disputas, dos conflitos e das negociações constitutivos das posições que os sujeitos ocupam (Louro, 2001, p.10).

Colocar o corpo na centralidade desse processo decolonial é problematizar um

\footnotetext{
${ }^{27}$ La reflexión pedagógica partió por problematizar el concepto de uni-versidad em sentido restrictivo de un universo, para ampliarlo a la visión múltiple de la realidad polisémica. Estas definiciones surgieron de mirar com detenimiento las logicas de las comunidades negras, sus formas de ver el mundo em sentido integral y sus relaciones con la naturaleza (...) Lo multi es asumido como la dimensión misma de la realidad em tanto que lo productivo, lo existencial, lo cosmogónico, lo social y lo cultural no están disociados sino que se inter-relacionan en un marco de tensiones, continuidades y rupturas creando un mundo plural (tradução nossa). ${ }^{28}$ A Teoria Queer emergiu no final da década de 1980, nos Estados Unidos, em oposição aos estudos da sociologia sobre as "minorias sexuais". 0 termo "queer" é um xingamento que denominava "anormalidade": "Teórica e metodologicamente, os estudos queer surgiram do encontro entre uma corrente da Filosofia e dos Estudos Culturais norte-americanos com o pós-estruturalismo francês, que problematizou concepções clássicas de sujeito, identidade, agência e identificação. Central foi o rompimento com a concepção cartesiana (ou lluminista) do sujeito como base de uma ontologia e de uma epistemologia. Ainda que haja variações entre os diversos autores, é possível afirmar que o sujeito no pós-estruturalismo é sempre encarado como provisório, circunstancial e cindido" (Miskolci, 2009, p.152).
} 
dos pilares da colonialidade/modernidade. Esse parece ser o mote dos artivismos queer quando pretendem utilizar o corpo como arte para criar um outro agenciamento que não esteja focado somente na perspectiva rígida identitária, político-partidária ou na reivindicação de marcos legais e jurídicos que são incapazes de questionar e modificar o que Rolnik $(2016$, p.8) chama de "inconsciente colonial capitalístico que comanda o sujeito moderno ocidental que todavia encarnamos, inclusive nas esquerdas". Para fazer frente a essa subjetividade vigente, ela propõe o que chama de uma micropolítica ativa (e não reativa, que seria a dominante, incentivada e fomentada pelo capitalismo globalitário financeirizado). Para fazer isso,

[...] não basta tomar para si a responsabilidade como cidadão (o mínimo indispensável, insisto): é preciso, mais amplamente, tomar para si a responsabilidade enquanto ser vivo, de modo a agir no sentido de uma micropolítica ativa. Essa é a condição para nos tornarmos agentes de criação de modos de existência coletivos, o que começa em nossa existência, mas por princípio não termina nela (...) Isso depende de uma desidentificação com os modos de existência que o Capitalismo Mundial Integrado (CMI) constrói no lugar daqueles que devastou (Rolnik, 2016, p.30-31).

\section{Forclusão $^{29}$}

Além de criar aproximações entre os conceitos de Deleuze e Guattari, o procedimento cartográfico, a decolonialidade e a teoria queer, esse artigo se propôs a apontar alguns caminhos, linhas de investigação a respeito da produção do Teatro Oficina Uzyna Uzona e a Universidade Antropófaga, no que diz respeito ao corpo como centralidade da transmissão desse conhecimento.

A missão educadora, ou melhor falando em termos de decolonialidade, deseducadora, sempre foi um horizonte para o Oficina, ora por que é da natureza desse teatro colocar em xeque nossas convicções em vistas a uma visão libertadora do mundo, ora pelo caráter de subversão na operação de desmonte do Teatro brasileiro, produto da colonização, vide José de Anchieta e sua catequese.

Em termos moleculares, quem sabe não seja o caminho da subversão do próprio corpo uma maneira de nos livrarmos das intersubjetividades construídas? Criar outros Corpos Sem Órgãos que não sejam construídos pelo eurocentrismo e sua operação de colonização do conhecimento: a modernidade/colonialidade.

Até lá, num sentido utópico, mas não no mesmo sentido das velhas esquerdas, ou, até lá no passado (pensando que o tempo também é produto do moderno/colonial), o nu não seja visto como problema. Como num espetáculo do Oficina, como em um concurso de Monstrxs ${ }^{30}$ no Âncora do Marujo. Corpos celebrando potências, como num tempo mítico originário e inexistente, que remonta aos coletores caçadores, ou a não-existência do Urstaat, ${ }^{31}$ pré-século XV, pré-edipiano (e já não sendo por

\footnotetext{
${ }^{29} \mathrm{~A}$ forclusão é um termo lacaniano (psicanalista francês Jacques Lacan 1932-1981) para designar aquilo que perdeu seu efeito por não ter sido registrado no tempo certo. É uma desordem nas relações do "real" e do "simbólico": "[...] a presença de Édipo só aparece através da sua ausência patente, compreendida como um efeito do recalcamento, ou melhor ainda, já que o invariante estrutural só é descoberto através de variações imaginárias, como testemunhos, se preciso, de uma forclusão simbólica (o pai como lugar vazio)" (Deleuze; Guattari, 2010, p.227). Aqui o termo forclusão é utilizado em substituição a qualquer outro que pudesse sugerir "conclusão" ou "considerações finais", por se tratar de uma investigação multidisciplinar em andamento e que perpassa vários campos.

${ }^{30}$ Concurso que ocorreu de janeiro a março de 2017 numa pequena casa de espetáculos da avenida Carlos Gomes, centro decadente de Salvador, e que, rasurando um território LGBT, foi tomado por uma multidão queer (Preciado, 2017) de subjetividades que superam a ideia binomial de homo/hetero, homem/mulher.
} 
citá-lo), 4 (+n), minutos antes do colonizador chegar e ser surpreendido com nossa inocência nua.

\section{Referências}

ACHINTE, Adolfo Alban. Conocimiento y lugar: más allá de la razón hay un mundo de colores. In: ACHINTE, Adolfo Alban (Org.)Texiendo textos y saberes. Cinco hilos para pensar los estudios culturales, la colonialidad y la interculturalidad. Colombia: Editorial Universidad del Cauca, 2006, p.59 - 82.

ANDRADE, Wellington. Artaud e Zé Celso, dois momos heresiarcas. Revista Cult, São Paulo, 2015. Disponível em: http://revistacult.uol.com.br/home/2015/03/artaud-eze-celso-dois-momos-heresiarcas/. Acesso em: 12 jan. 2017.

ANDRADE, Oswald. O Santeiro do Mangue e Outros Poemas. Rio de Janeiro: Editora Globo, 2012.

ARTAUD, Antonin. Pour finir avec le jugement Dieu [1947]. In: Oeuvres Completes, tomo XIII. Paris: Édition Galimard, 1974.

O Rei da Vela [1933]. São Paulo: Abril, 1976.

BALLESTRIN, Luciana. América Latina e o giro decolonial. Revista Brasileira Ciência Política, Brasília, n. 11, ago. 2013. Disponível em: http://www.scielo.br/scielo.php?script=sci_arttext\&pid=S0103-33522013000200004\&lng=en\&nrm=iso. Acesso em: 16 Mar.2017.

BRECHT, Bertold. Teatro Completo V.2: Na selva das cidades (1923), A vida de Eduardo II da Inglaterra, Um homem é um homem. São Paulo: Editora Paz e Terra, 2009.

BUTLER, Judith. Problemas de gênero: feminismo e subversão da identidade. Rio de Janeiro: Civilização Brasileira, 2003.

CAMPBELL, Patrick George Warburton. Narciso ctônico: Os Sertões e a (r)evolução estética do Teat(r)o Oficina Uzyna Uzona - uma escritura desconstrucionista. Salvador, 2011. Tese (Doutorado) - Escola de Teatro, Universidade Federal da Bahia.

CUNHA, Euclides da. Os Sertões. São Paulo: Ateliê Editorial, Imprensa Oficial do Estado, Arquivo do Estado, 2001.

DELEUZE, Gilles; GUATTARI, Felix. O anti-Édipo: capitalismo e esquizofrenia. São Paulo: Editora 34, 2010.

\footnotetext{
${ }^{31}$ Estado originário, primitivo, "ponto de partida de Abraão ou de uma nova aliança. O Estado não se formou progressivamente, mas surgiu de uma vez já todo armado, num golpe de mestre [...]" (Deleuze; Guattari, 2010, p. 287)
} 
. Mil platôs: capitalismo e esquizofrenia 2, vol.1.

São Paulo: Editora 34, 1995.

DERRIDA, Jacques. A Diferença. In: Margens da filosofia. Campinas-Sp: Papirus, 1991, p. 33-63.

GLISSANT, Édouard. Introdução a uma poética da diversidade. Juiz de Fora: Editora UFJF, 2005.

GORKI, Maximo. Pequenos burgueses [1902]. São Paulo: Editora Hedra, 2010.

Os inimigos [1906]. Porto Alegre: L\&Pm Pocket, 1997.

GROSFOGUEL, Ramón. Del extractivismo económico al extractivismo epistémico y extractivismo ontológico: una forma destructiva de conocer, ser y estar en el mundo. Tabula Rasa, Colômbia, jan. 2016. Disponível em: http://www.redalyc.org/articulo. oa?id=39646776006 Acesso em: 10 mar. 2017.

KOPENAWA, Albert Bruce Davi. A queda do céu: palavras de um xamã yanomami. São Paulo: Companhia das Letras, 2015.

LIMONGI, Joana Alice Pinheiro. Fazer um múltiplo brasileiro: José Celso Martinez Corrêa, Uzyna Uzona e a montagem de Os Sertões. Brasília, 2008. Dissertação (Mestrado). Centro de Artes, Universidade de Brasília.

LOURO, Guacira Lopes. Teoria Queer: uma política pós-identitária para a educação. Revista Estudo Feminista, Florianópolis, v. 9, n.2, p. 541-553, 2001.

MARTINEZ CORREA, José Celso; BARDI, Lina Bo; ELITO, Edson. Teatro Oficina 19801984. Lisboa: Printer Portuguesa S.A., 1999.

MARTINEZ CORREA, José Celso. Primeiro ato: cadernos, depoimentos, entrevistas (1958-1974). São Paulo: Editora 34, 1998.

. O terreiro eletrônico e a cidade: o olhar do mestre antropófago. Sala Preta, São Paulo, v. 12, n. 1, p. 209-223, 2012.

pra dar um FIM NO JUIZO d deus afinal q o dia

d'Ela chegou. Blog do Zé Celso: mar. 2016. Disponivel em: https://blogdozecelso. wordpress.com/2016/03/29/pra-dar-um-fim-no-juizo-d-deus-afinal-q-o-dia-delachegou/ Acesso em: 16 mar. 2017.

MISKOLCl, Richard. A Teoria Queer e a Sociologia: o desafio de uma analítica da normalização. Sociologias, Porto Alegre, ano 11, n. 21, p.150-182, jan/jun.2009. 
NANDI, Ítala. Teatro Oficina onde a arte não dormia. Rio de Janeiro: Nova Fronteira, 1989.

NUNES, Fábio. O Oficina hoje: entrevista com Camila Mota. Esquerda Diário: Naufrágio - coluna indisciplinada de arte e política, São Paulo, jan. 2017. Disponível em: http://www.esquerdadiario.com.br/Naufragil-coluna-indisciplinada-de-arte-e-politica-12097 Acesso em: 16 mar. 2017.

PIRES, Ericson. Zé Celso e a Oficina-Uzyna de Corpos. São Paulo: Anablume, 2005.

PORTAL UNIVERSIDADE ANTROPÓFAGA, 2017. Disponível em www.universidadeantropofaga.org Último acesso em 17 jun. 2017.

PRECIADO, Paul. Cartografia Queer: o Flâneur Perverso, a Lésbica Topofóbica e a Puta Multicartográfica ou Como Fazer uma Cartografia 'Zorra' com Annie Sprinkle. Erevista Performatus, Inhumas, ano 5, n.17, jan. 2017.

QUIJANO, Anibal. Colonialidade do poder, eurocentrismo e América Latina. In: LANDER, Edgardo (Org.). A colonialidade do saber: eurocentrismo e ciências sociais. Buenos Aires: Perspetivas latino-americanas CLACSO, 2005, p. 107-127.

RAMOS, Luiz Fernando. O parto de Godot: e outras encenações imaginárias: a rubrica como poética da cena. São Paulo: Hucitec/Fapesp, 1999.

ROLNIK, Suely. A hora da micropolítica. São Paulo: Série Pandemia, número 1, 2016.

SÁ, Nelson de. O que foi publicado sobre Para Dar Um Fim no Juízo de Deus. Folha de S.Paulo, São Paulo, 11 fev. 1997. Disponível em: http://www.teatroficina.com.br/ posts/7 Acesso em: 16 mar. 2017.

SÁEZ, Javier; CARRASCOSA, Sejo. Por el culo - políticas anales. Madri: Egales, 2011.

SARTRE, Jean Paul. As moscas [1943]. São Paulo: Nova Fronteira, 2013.

A engrenagem [1948]. Lisboa: Editora Presença, 1964.

SILVA, Armando Sérgio. Oficina: do teatro ao te-ato. São Paulo: Perspectiva, 2008.

SOUSA, Maria Angélica Rodrigues de. Quando corpos se fazem arte: uma etnografia sobre o Teatro Oficina. São Carlos, 2013. Dissertação (Mestrado). Universidade Federal de São Carlos.

TROI, Marcelo de. COLLING, Leandro. Antropofagia, dissidências e novas práticas: o Teatro Oficina. Revista Ambivalências, Aracaju, v.4, n.8, p. 125 - 146, dez. 2016. Dispo- 
nível em: http://www.seer.ufs.br/index.php/Ambivalencias/article/view/6004 Acesso em: 01 mar. 2017.

VERGUEIRO, Viviane. Por inflexões decoloniais de corpos e identidades de gênero inconformes: uma análise autoetnográfica da cisgeneridade como normatividade. Salvador, 2015. Dissertação (Mestrado). Universidade Federal da Bahia.

WOLFE, Thomas. Look Homeward, Angel: a story of the Buried Life [1929]. New York: Charles Scribner's Sons, 2016.

Recebido em: 27/03/2017 Aprovado em: 25/06/2017 